\title{
EFEK ANTIINFLAMSI EKSTRAK HERBA KEROKOT (Lygodium microphyllum Cav.) TERHADAP TIKUS PUTIH (Rattus norvegicus)
}

\author{
Nurina Khairana L. *, Risna Agustina, Adam M. Ramadhan \\ Laboraturium Penelitian dan Pengembangan FARMAKA TROPIS \\ Fakultas Farmasi Universitas Mulawarman, Samarinda, Kalimantan Timur \\ *email: nurinakhairana42@gmail.com
}

\begin{abstract}
ABSTRAK
Tumbuhan kerokot secara empiris digunakan masyarakat untuk pengobatan demam dan nyeri otot serta memiliki potensi sebagai obat luka. Penelitian ini bertujuan untuk mengetahui aktivitas herba kerokot sebagai antiinflamasi. Metode yang digunakan yaitu paw edema dengan induksi karagenan pada tikus putih. Tikus putih dikelompokan menjadi lima kelompok yaitu kelompok kontrol negatif yang diberikan Na-CMC 1\%, kelompok kontrol positif yang diberikan natrium diklofenak $50 \mathrm{mg}$, dan tiga kelompok uji yang diberikan ekstrak dengan tiga variasi dosis yaitu $100 \mathrm{mg} / \mathrm{kgBB}, 150 \mathrm{mg} / \mathrm{kgBB}$ dan $200 \mathrm{mg} / \mathrm{kgBB}$ yang masing-masing diberikan secara oral kemudian diinduksi karagenan 1\% agar mengalami edema. Pengukuran volume edema kaki tikus putih menggunakan alat pletismometer setiap 60 menit selama 7 jam. Hasil analisis data pengujian menunjukkan bahwa ketiga dosis uji memiliki aktivitas sebagai antiinflamasi, kemudian ekstrak herba kerokot memiliki dosis efektif sebesar $150 \mathrm{mg} / \mathrm{kgBB}$ dan memiliki potensi yang sama dengan natrium diklofenak $50 \mathrm{mg}$.
\end{abstract}

Kata Kunci: Lygodium microphyllum Cav., Antiinflamasi, Tikus Putih

\begin{abstract}
Empirically Lygodium microphyllum used by the community to treat fever, muscle painful and have potential as injury medicine. The purpose of this research is to gain an understanding about the anti-inflammatory activity of Lygodium microphyllum Cav.This research use the paw edema method by inducing the carrageenan on white mouse's feet. White mouse were categorized as five group which were group in negative control which given Na-CMC 1\%, positive control which were given Sodium Diclofenac 50mg and three test group given extract with three variation doses which were $100 \mathrm{mg} / \mathrm{kg} \mathrm{BW}, 150 \mathrm{mg} / \mathrm{kg} \mathrm{BW}$ and $200 \mathrm{mg} / \mathrm{kg} \mathrm{BW}$ orally and than given to each mouse that induction by carrageenan $1 \%$ for edema. The measured of edema volume on mouse feet using a pletysmometer every 60 minutes for 7 hours. The results of data analysis showed that three doses have effect to antiinflamation, and than Lygodium microphyllum extract have effective dose in 150 $\mathrm{mg} / \mathrm{kgBB}$ and has same potential with natrium diklofenak $50 \mathrm{mg}$.
\end{abstract}

Keywords : Lygodium microphyllum Cav., Anti-inflammatory., White mouse

\section{PENDAHULUAN}

Tumbuhan kerokot masih dianggap gulma oleh masyarakat Kalimantan Timur karena kemampuannya yang tumbuh cepat dan meluas ke segala arah dalam suatu areal lahan perkebunan sehingga mengganggu tanaman petani. Masyarakat memanfaatkan daun dan akarnya sebagai obat demam dan nyeri otot. Telah dilakukan skrining beberapa potensi 
kefarmasian terhadap ekstrak herba kerokot dan terbukti memliki potensi sebagai antioksidan dan obat luka (Rijai, 2012).

Bengkak merupakan salah satu tanda terjadinya inflamasi. Inflamasi adalah mekanisme respons tubuh terhadap kerusakan seluler (Barber, 2012). Kerusakan tersebut ditandai dengan rubor, kalor, dolor, tumor dan fungsio laesa (Price, 2006).

Kandungan kimia herba kerokot diantaranya adalah flavonoid. Dari berbagai jurnal diketahui bahwa flavonoid dapat digunakan sebagai antiinflamasi. Aktivitas antiinflamasi flavonoid dengan penghambatan pada enzim siklooksigenase atau lipooksigense (Hidayati, 2005). Berdasarkan uraian di atas diketahui belum adanya informasi yang lengkap mengenai efek farmakologi herba kerokot sebagai antiinflamasi, maka dilakukan penelitian aktivitas antiinflamasi pada ekstrak herba kerokot.

\section{METODE PENELITIAN}

\section{Bahan}

Bahan yang digunakan dalam penelitian ini adalah simplisia herba kerokot, etanol 96\%, karagenan, $\mathrm{NaCl}$ fisiologis $0,9 \%$, natrium diklofenak, $\mathrm{Na}-\mathrm{CMC}$ dan air suling.

Hewan percobaan yang digunakan adalah tikus putih jantan berumur sekitar 3-4 bulan dengan berat 130-220 gram dan sehat.

\section{Peralatan}

Alat-alat yang digunakan dalam penelitian ini adalah alat untuk maserasi, rotary evaporator, timbangan analitik, inkubator, cawan porselin, spoid, sonde, labu ukur, pletismometer dan alat gelas penunjang lainnya.

\section{Prosedur}

\section{Pengumpulan Sampel}

Herba kerokot diambil pada pagi hari dengan cara diputus lilitannya pada batang pohon. Dilakukan sortasi basah pada herba kerokot untuk memisahkan kotoran-kotoran yang terdapat pada tumbuhan. Herba dicuci dengan air mengalir untuk menghilangkan pengotor yang melekat. Kemudian herba kerokot dirajang untuk mempermudah proses pengeringan dan ekstraksi. Dilakukan sortasi kering untuk mrnghilangkan pengotor yang masih tertinggal. Kemudian ditimbang berat simplisia kering herba kerokot yang dihasilkan.

\section{Ekstraksi}

Herba kerokot diekstraksi dengan cara maserasi menggunakan pelarut etanol $96 \%$ selama 3 hari. Disaring menggunakan kertas saring dan ditampung di dalam wadah kemudian dipekatkan menggunakan rotary evaporator lalu dikering anginkan untuk mendapat ekstrak herba kerokot.

\section{Persiapan Hewan Uji}

Semua hewan uji dipelihara dalam kondisi yang sama. Sebelum digunakan, tikus diadaptasikan dengan lingkungan penelitian selama dua minggu dan sebelum pengujian tikus dipuasakan \pm 18 jam dengan tetap diberi minum

\section{Pengujian Aktivitas Antiinflamasi}

Dibagi tikus menjadi tiga kelompok yang masing-masing berisi 5 ekor tikus. Diberi tanda pada kaki tikus untuk memberi batas pada saat pengukuran pada alat. Kemudian dilakukan perlakuan pada masing-masing kelompok. 
Perlakuan yang diberikan pada masing-masing kelompok adalah

- Kontrol negatif suspensi Na CMC 1\%

- Kontrol positif suspensi obat natrium diklofenak $50 \mathrm{mg}$

- Kelompok uji 1; ekstrak etanol herba kerokot $100 \mathrm{mg} / \mathrm{kgBB}$

- Kelompok uji 2; ekstrak etanol herba kerokot $150 \mathrm{mg} / \mathrm{kgBB}$

- Kelompok uji 3; ekstrak etanol herba kerokot $200 \mathrm{mg} / \mathrm{kgBB}$

Setelah itu dilakukan pengukuran volume kaki tikus putih yang dinyatakan sebagai volume awal $\left(\mathrm{V}_{0}\right)$ dengan cara mencelupkan kaki tikus ke dalam bejana hingga tanda batas. Pada setiap pengukuran tinggi cairan pada alat harus sama.

Dibersihkan kaki tikus dengan alkohol, kemudian telapak kaki tikus diinduksi karagenan $1 \%$ sebanyak $0,1 \mathrm{~mL}$ secara intraplantar. Diukur volume udem kaki tikus setiap 60 menit selama 7 jam dengan pletismometer. Kemudian dianalisis menggunakan SPSS (Statistical Package for the Social Sciences).

Tabel 1 . Volume radang rata-rata telapak kaki tikus

\begin{tabular}{ccccccccc}
\hline \multirow{2}{*}{ Kelompok Uji } & \multicolumn{7}{c}{ Hasil rata-rata perubahan volume pada jam ke- } \\
\cline { 2 - 10 } & $\mathbf{0}$ & $\mathbf{1}$ & $\mathbf{2}$ & $\mathbf{3}$ & $\mathbf{4}$ & $\mathbf{5}$ & $\mathbf{6}$ & $\mathbf{7}$ \\
\hline Kontrol Negatif & 0 & 0,70 & 0,74 & 0,82 & 0,87 & 0,92 & 0,82 & 0,72 \\
Dosis 100 mg/kg BB & 0 & 0,69 & 0,69 & 0,64 & 0,57 & 0,49 & 0,30 & 0,13 \\
Dosis 150 mg/kg BB & 0 & 0,60 & 0,55 & 0,51 & 0,39 & 0,18 & 0,02 & 0 \\
Dosis 200 mg/kg BB & 0 & 0,53 & 0,46 & 0,36 & 0,33 & 0,16 & 0 & 0 \\
Kontrol Positif & 0 & 0,48 & 0,34 & 0,27 & 0,14 & 0,05 & 0 & 0 \\
\hline
\end{tabular}

\section{HASIL DAN PEMBAHASAN}

\section{Aktivitas Antiinflamasi Ekstrak Herba Kerokot}

Pengukuran volume udem pada telapak kaki tikus dilakukan setiap 60 menit selama 7 jam setelah telapak kaki tikus diinduksi karagenan agar terjadi inflamasi. Pengamatan selama 7 jam dilakukan untuk mengetahui waktu dimana volume radang maksimal terbentuk. Pada penelitian ini, volume radang rata-rata kelompok kontrol negatif yang diberikan Na-CMC meningkat mulai jam pertama sampai jam kelima, volume radang terbesar terjadi pada jam kelima. Lalu mulai mengalami penurunan pada jam keenam hingga ketujuh namun belum dapat mengembalikan volume radang pada kaki tikus sampaik ke volume normal.

Dari hasil penelitian menunjukkan bahwa ketiga variasi dosis ekstrak herba kerokot mampu menghambat radang. Volume radang pada telapak kaki tikus yang lebih kecil dari kelompok kontrol negatif menunjukkan bahwa ekstrak herba kerokot mampu menekan radang yang disebabkan oleh karagenan. Tampak adanya perbedaan volume radang antara kelompok kontrol negatif dan dosis ekstrak herba kerokot. Pada kelompok kontrol negatif yang diberikan $\mathrm{Na} \mathrm{CMC}$, volume radang meningkat mulai dari jam pertama sampai jam kelima, sedangkan pada kelompok perlakuan dosis $100 \mathrm{mg} / \mathrm{kgBB}$ volume radang mulai terjadi pada jam pertama kemudian pada jam kedua tidak terjai kenaikan maupun penurunan, lalu pada jam ketiga mengalami penurunan. Pada dosis $150 \mathrm{mg} / \mathrm{kgBB}$ dan $200 \mathrm{mg} / \mathrm{kgBB}$, peningkatan volume radang mulai terjadi pada jam pertama dan kemudian mulai mengalami penurunan volume bengkak pada jam kedua. Untuk lebih jelasnya dapat dilihat pada gambar 1. 


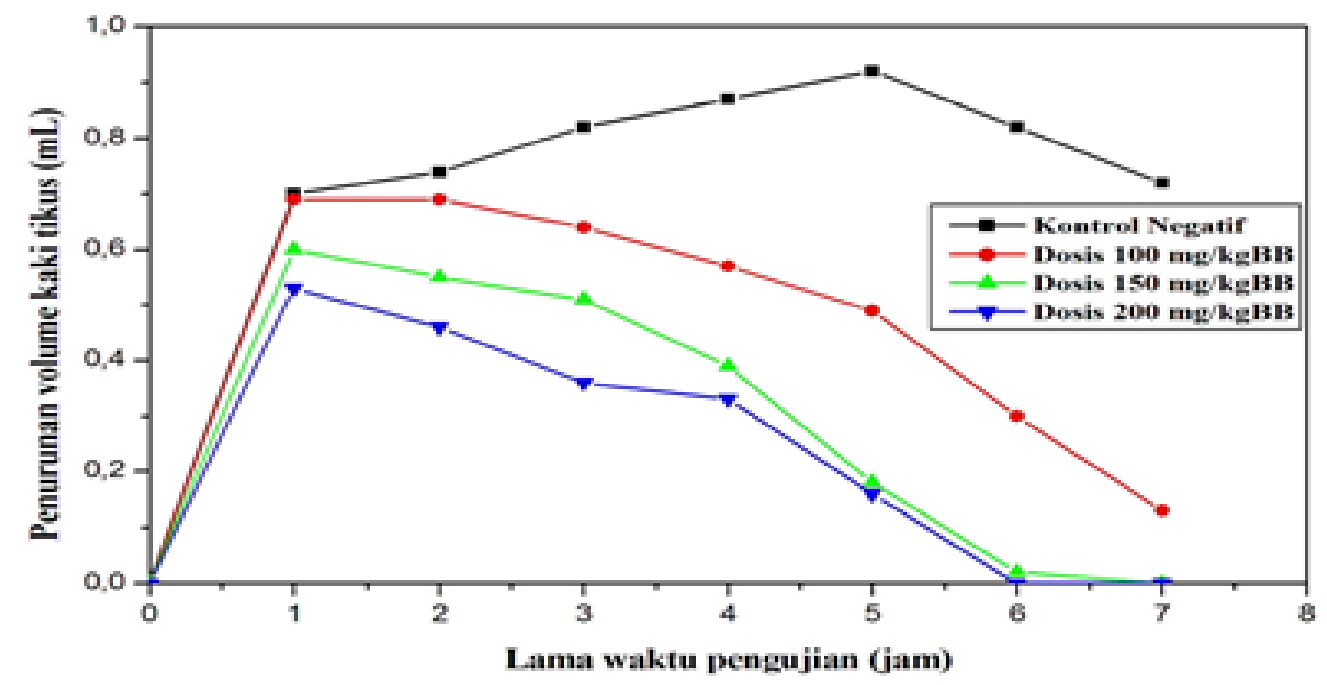

Gambar 1. Grafik perbandingan penurunan volume kaki tikus putih kelompok kontrol negatif dengandosis ekstrak etanol herba kerokot

Dapat disimpulkan dapat diketahui bahwa semua variasi dosis ekstrak memiliki tingkatan yang berbeda-beda dalam menurunkan volume radang pada kaki tikus putih. Hal ini membuktikan bahwa semakin besar konsentrasi dari dosis uji ekstrak herba kerokot maka akan semkin besar pula aktivitas antiinflamasi yang diberikan.

\section{Dosis Efektif Ekstrak Herba Kerokot}

Analisis data yang digunakan dalam penentuan dosis efektif sebagai antiinflamasi adalah dengan menggunakan uji statistika berupa uji homogenitas data, uji signifikansi pengaruh variasi dosis terhadap aktivitas antiinflamasi dan uji duncan pada SPSS (Statistical Package for the Social Sciences)

Hasil analisis statistik uji kenormalan data menunjukkan bahwa nilai sig $>0,05$, dengan demikian maka dapat disimpulkan bahwa data yang diperoleh terdistribusi secara normal atau homogen. Kemudian, setelah dilakukannya uji kenormalan data, dilanjutkan dengan analisis uji signifikansi pengaruh variasi dosis terhadap aktivitas antiinflamasi.

Hasil analisis uji signifikansi pengaruh variasi dosis terhadap aktivitas antiinflamasi diperoleh nilai sig $<0,05$, dengan demikian dapat disimpulkan bahwa terdapat pengaruh yang signifikan antara variasi dosis uji ekstrak herba kerokot terhadap aktivitas antiinflamasi yang dihasilkan.

Berdasarkan uji duncan dapat diketahui bahwa kontrol negatif berada dalam subset yang berbeda dengan variasi dosis ekstrak. Hal ini menunjukkan bahwa aktivitas antiinflamasi kontrol negatif berbeda signifikan dengan masing-masing variasi dosis ekstrak. Diketahui bahwa ekstrak dosis $100 \mathrm{mg} / \mathrm{kgBB}$ juga berada pada subset yang berbeda dari kontrol negatif dan variasi dosis $150 \mathrm{mg} / \mathrm{kgBB}$ dan $200 \mathrm{mg} / \mathrm{kgBB}$, hal ini menandakan bahwa adanya perbedaan yang signifikan pada dosis $100 \mathrm{mg} / \mathrm{kgBB}$ dengan kontrol negatif dan dosis $150 \mathrm{mg} / \mathrm{kgBB}$ serta $200 \mathrm{mg} / \mathrm{kgBB}$. Pada dosis $150 \mathrm{mg} / \mathrm{kgBB}$ dan $200 \mathrm{mg} / \mathrm{kgBB}$ berada pada pada subset yang sama, hal ini menunjukkan bahwa tidak terdapat perbedaan yang signifikan antara ekstrak dosis $150 \mathrm{mg} / \mathrm{kgBB}$ dengan ekstrak dosis $200 \mathrm{mg} / \mathrm{kgBB}$ terhadap aktivitas antiinflamasi yang dihasilkan. Berdasarkan uji tersebut dapat diketahui bahwa dosis efektif yang beraktivitas sebagai antiinflamasi adalah dosis $150 \mathrm{mg} / \mathrm{kgBB}$. Ekstrak dosis $150 \mathrm{mg} / \mathrm{kgBB}$ dipilih sebagai dosis ekstrak efektif karena dosis tersebut 
memiliki aktivitas antiinflamasi yang tidak berbeda signifikan dengan dosis ekstrak terbaik (dosis ekstrak $200 \mathrm{mg} / \mathrm{kgBB}$ ).

\section{Potensi Antiinflamasi Ekstrak Herba Kerokot}

Pengumpulan data dilakukan dengan melakukan uji potensi dengan cara membandingkan dosis uji efektif ekstrak (dosis uji ekstrak $150 \mathrm{mg} / \mathrm{kgBB}$ ) dengan kontrol positif (suspensi natrium diklofenak $50 \mathrm{mg}$ ). Uji potensi ekstrak dengan kontrol positif dilakukan menggunakan uji t.

Berdasarkan uji t diperoleh nilai sig dari dosis uji efektif ekstrak dan kontrol positif $>0,05$, hal ini menunjukkan bahwa dosis uji efektif ekstrak dan kontrol positif tidak berbeda secara signifikan dalam memberikan efek antiinflamasi. Dengan demikian bahwa ekstrak herba kerkot dapat dikatakan berpotensi sebagai antiinflamasi dibandingkan dengan kontrol positif.

Natrium diklofenak merupakan penghambat siklooksigenase yang relatif nonselektif dengan daya antiinflamasi yang paling kuat. Siklooksigenase dari metabolisme asam arakidonat dapat menghasilkan prostglandin-prostaglandin yang mempunyai efek pada pembuluh darah, ujung-ujung saraf dan pada sel-sel yang terlibat dalam inflamasi. Jadi siklooksigenase merupakan prekursor dari sejumlah mediator inflamasi. Apabila enzim siklooksigenase dihambat maka sintesa prostaglandin tidak akan terjadi. Akibatnya, terjadi perubahan permeabilitas vaskular dan modulasi leukosit tidak terjadi. Apabila hal ini terjadi, maka inflamasi tidak akan terbentuk. Selain itu kelebihan dari natrium diklofenak yakni mempunyai waktu paruh yang singkat dan mempunyai efek samping yang lebih sedikit jika dibandingkan dengan antiinflamasi nonsteroid lainnya.

\section{KESIMPULAN}

Ekstrak etanol herba kerokot mempunyai aktivitas antiinflamasi pada dosis 100 $\mathrm{mg} / \mathrm{kgBB}$, dosis $150 \mathrm{mg} / \mathrm{kgBB}$ dan dosis $200 \mathrm{mg} / \mathrm{kgBB}$, dosis efektif sebagai antiinflamasi adalah dosis $150 \mathrm{mg} / \mathrm{kgBB}$, dan dosis $150 \mathrm{mg} / \mathrm{kgBB}$ dapat berpotensi sebagai antiinflamasi dibandingkan dengan natrium diklofenak $50 \mathrm{mg}$.

\section{DAFTAR PUSTAKA}

Barber, P., Robertson, D. 2012. Intisari Farmakologi untuk Perawat. EGC: Jakarta.

Hidayati, N. A., Listyawati, S dan Setyawan, A.D. 2005.

Kandungan Kimia dan Uji AntiInflamasi Ekstrak Etanol Lantana camara L. Pada Tikus Putih (Rattus novergicus L.) Jantan. Jurnal Bioteknologi. Vol 5. No 1.

Price, S. A. 2006. Patofisiologi: Konsep Klinis Proses-Proses Penyakit Edisi 6. EGC: Jakarta.

Rijai, L. 2012. Potensi Tumbuhan Kerokot (Lygodium microphylum) Dalam Bidang Kefarmasian. Jurnal Tropical Phamachy Chemistry 2012 Vol 2. No. 1. 